\section{Estudo cobebate}

em Cestão Planejamento
Revista Estudo \& Debate, Lajeado, v. 25, n. 2, 2018. ISSN 1983-036X DOI: http://dx.doi.org/10.22410/issn.1983-036X.v25i2a2018.1742

\title{
CARACTERÍSTICAS COMPORTAMENTAIS EMPREENDEDORAS: EM CENA OS FUTUROS MÉDICOS VETERINÁRIOS ${ }^{1}$
}

\author{
Cristiane Krüger ${ }^{2}$, Italo Fernando Minello ${ }^{3}$, Caroline dos Santos Porto ${ }^{4}$
}

\begin{abstract}
Resumo: Neste estudo objetivou-se analisar as características comportamentais empreendedoras mais evidentes nos discentes de graduaçáo do curso de Medicina Veterinária da UFSM. Especificamente traçou-se o perfil dos discentes, identificou e comparou-se tais características de acordo com o gênero dos discentes. Trata-se de um estudo descritivo, com abordagem quantitativa, para tal, aplicou-se o questionário de características comportamentais empreendedoras de McClelland. Os resultados apontam que a característica estabelecimento de metas foi a que mais se destacou entre os discentes. No que se refere à comparação das características comportamentais empreendedoras diante do gênero, evidencia-se que ambos sexos apresentam as dez características. Os homens apresentam maiores médias em cinco características e as mulheres em quatro. Quanto as dimensôes, as mulheres apresentam maior pontuação em realização, e os homens em planejamento e poder. No entanto, não houve diferenças expressivas de média entre os gêneros. O estudo traz contribuiçóes quanto ao perfil empreendedor dos alunos de graduaçáo, pela qual a instituição pesquisada pode se apossar para melhor preparar os discentes para a sociedade. No estudo limitou-se ao instrumento aplicado, exclusivamente no curso de graduação em Medicina Veterinária da UFSM, para estudos futuros sugere-se a replicação da pesquisa em outros cursos em diferentes instituiçōes.
\end{abstract}

Palavras-chave: Empreendedorismo; Comportamento empreendedor; Características empreendedoras.

1 Texto inicial apresentado e publicado em: PORTO, Caroline dos Santos; KRÜGER, Cristiane; MINELLO, Italo Fernando. Características Comportamentais Empreendedoras: Em cena os futuros médicos veterinários. In: FÓRUM INTERNACIONAL ECOINOVAR, 6., 2017, Santa Maria-RS. Anais... Santa Maria-RS, ECOINOVAR, 2017.

2 Bacharel em Ciências Contábeis. Contadora CRCRS 091244/O. Especialista em Contabilidade, Pericia e Auditoria. Graduada no Programa Especial de Formação de Professores para Educação Profissional - PEG, Especialista em Gestáo Pública, Mestra em Administraçáo pela Universidade Federal de Santa Maria e, atualmente, doutoranda em Administração pela Universidade Federal de Santa Maria.

3 Doutor em Administração pela FEA-USP. Professor no Programa de Pós-Graduação na Universidade Federal de Santa Maria.

4 Possui graduação em Administração com especialização em Comunicação e Marketing em Mídias Digitais e TICs Aplicadas à Educação. 


\title{
ENTREPRENEURIAL BEHAVIORAL CHARACTERISTICS: AT THE SCENE THE VETERINARY MEDICAL FUTURES
}

\begin{abstract}
This study aimed to analyze the most evident entrepreneurial behavioral characteristics in undergraduate students of the UFSM Veterinary Medicine course. Specifically the profile of the students was traced, identified and compared such characteristics according to the genre of the students. It is a descriptive study, with a quantitative approach, for this purpose the questionnaire of entrepreneurial behavioral characteristics of McClelland was applied. The results indicate that the characteristic goal setting was the one that stood out the most among the students. With regard to the comparison of entrepreneurial behavioral characteristics in relation to gender, it is evident that both sexes present the ten characteristics. Men presented higher averages in five characteristics and women in four. As for dimensions, women score higher on achievement, and men on planning and power. However, there were no significant differences between the genders. The study provides contributions on the entrepreneurial profile of undergraduate students, through which the research institution can get hold of to better prepare the students for the society. In the study it was limited to the applied instrument, exclusively in the undergraduate course in Veterinary Medicine of the UFSM, for future studies it is suggested the replication of the research in other courses in different institutions.
\end{abstract}

Keywords: Entrepreneurship; Entrepreneurial behavior; Entrepreneurial characteristics.

\section{INTRODUÇÃO}

O empreendedorismo, para Carreira et al. (2015), pode ser compreendido como uma oportunidade que um indivíduo cria ou aproveita na sociedade, podendo desenvolver uma atividade econômica organizada, gerando valor para si e para o mercado.

Seguindo esse conceito, para Souza e Santos (2014), é fundamental, no mundo moderno, que as pessoas estejam preparadas para aprender a agir e pensar com criatividade, utilizando a liderança e visão de futuro para inovar. Para esses autores os empreendedores são peças chaves para o sucesso de uma organização, pois são dotados de habilidades que os impulsionam para agir antecipadamente buscando encontrar soluçóes satisfatórias no cenário que estão expostos, resolvendo problemas, assumindo responsabilidades, alcançando objetivos.

O estudo sobre empreendedorismo para Brandão, Vasconcelos e Muniz (2011), não está apenas atrelado ao universo empresarial, no processo de criação de empresas e na busca por lucro, mas também se encontra evidente no ponto de vista pessoal como atuante na transformação do seu meio e na geração de conhecimento. Somando-se a isso Brancher, Oliveira e Roncon (2012) contribuem afirmando que o fenômeno do empreendedorismo está a favor das iniciativas de unir talentos, renovando e inovando dentro e fora de uma organização, permitindo que o desenvolvimento aconteça.

Seguindo esse raciocínio infere-se que é de suma importância incluir o ensino do empreendedorismo em todos os níveis de formação acadêmica, logo, a educação empreendedora é compreendida como um meio para despertar o espírito e comportamento empreendedor nas pessoas (FILHO; BRUNI, 2015). Nessa perspectiva, Ribeiro e Bernardes (2014) corroboram que as instituições de ensino têm atuação fundamental quando se trata do desenvolvimento das características necessárias para os alunos serem capazes de viabilizar oportunidades mas, isso não requer apenas disposição dos docentes, mas sim a mudança do comportamento dos próprios alunos. 
Para definir quais são essas características Câmara e Andalécio (2012) explanam que existe uma ampla literatura que faz referência sobre o que são os empreendedores e suas caraterísticas mais evidentes. Os autores salientam que as características dos empreendedores que apareceram com mais frequência são: inovação, liderança, riscos moderados, independência, criatividade, energia, tenacidade, originalidade, otimismo, orientação para resultados, flexibilidade, iniciativa, envolvimento em longo prazo, autoconfiança, agressividade, sensibilidade a outros, tendência a confiar nas pessoas, dinheiro como medida de desempenho, etc. Dentre estas características, destacam-se as dez características comportamentais empreendedoras desenvolvidas a partir dos estudos de McClelland (MSI, 1990).

Essas características podem se expressar diferentemente entre homens e mulheres, devido às suas distinçôes naturais. Homens e mulheres passam por experiências distintas desde a infância e isto pode influenciar na sua formação e características enquanto profissionais (MINUZZI; VARGAS; FIALHO, 2016). No entanto, para Machado (2008) o empreendedorismo não é privilégio de nenhum dos gêneros.

Nesse cenário, se inserem os futuros médicos veterinários, atualmente discentes de graduação, os quais necessitam cada vez mais desenvolver características comportamentais empreendedoras para que estejam preparados para competir no ambiente profissional que os aguarda. Segundo Euromonitor (2015), a quantidade de profissionais Médicos Veterinários teve um crescimento de $416,9 \%$ entre 2001 a 2015, além disso, ocorreu um aumento no número de estabelecimentos empresariais voltados à essa profissão (EUROMONITOR, 2015).

Os médicos veterinários atuam cada vez mais como proprietários de seus próprios negócios, conforme Freitas e Gamero (2018), o exercício da Medicina Veterinária emprega contingente significativo de profissionais, para os autores além das competências tradicionais se faz necessário o aprendizado de como gerir a carreira e os empreendimentos relacionados à profissão, o que motivou a realização deste estudo, visto que se pesquisou o comportamento empreendedor desses estudantes.

Nesse sentido, objetivo do presente estudo é analisar as características comportamentais empreendedoras mais evidentes nos discentes de graduação do curso de Medicina Veterinária da UFSM. Especificamente pretende-se traçar o perfil dos discentes, identificar e comparar as características comportamentais empreendedoras de acordo com o gênero desses discentes.

\section{COMPORTAMENTO EMPREENDEDOR}

Diante do atual cenário socioeconômico, Dornelas (2014) afirma que se passa por constantes transformaçōes na criação de novas invenções que estão mudando o estilo de vida das pessoas. $\mathrm{O}$ autor frisa que para obter novas criaçōes é preciso inovação, logo, é necessário pessoas ou equipes que possuam caraterísticas especiais, visionárias, que fazem as coisas aconteceres e empreendem. Os empreendedores são pessoas singulares, são apaixonados pelo que fazem, querem ser reconhecidos, referenciados e imitados (DORNELAS, 2014). 
De acordo com Dolabela (1999) o empreendedorismo é contemplado tanto com o empreendedor que é resultado de seus negócios e sua medida de desempenho é baseada pelo seu capital financeiro. E também pelo empreendedor na área de pesquisa e ensino, que é mensurado pelo potencial de agregação de valores propagados e geração de novos conhecimentos e novas tecnologias.

No empreendedorismo, como assinalam Dolabela e Filion (2013), a mudança deve começar pela base e não pelo topo, a sociedade deve abordar práticas que permitam mudanças estruturais, empresariais e que sejam integradas ao sistema social recriando padróes nos processos de aprendizagem. O empreendedorismo é capaz de transformar todos os indivíduos em protagonistas de seus destinos, agir para uma integração que altere sua relação com o mundo e com os outros além de se reinventar a si mesmo.

Para Hisrich, Peters e Shepherd (2014), os empreendedores pensam diferente das outras pessoas, tomam decisóes em ambientes inseguros, com altos riscos, intensas pressóes de tempo e concebível investimento emocional. Clemente e Almeida (2013) colaboram que o empreendedor vive em um cotidiano intenso repleto de duvidas e decisóes difíceis, cercado pelo cenário econômico, politico e social, é um individuo destemido e pesa fundamental para o crescimento econômico de qualquer nação, pois se transforma e aprendem novas tecnologias, práticas e conceito sobre produtos e serviços.

Vidal e Santos Filho (2003) realizaram um estudo com um gerente - proprietário de uma empresa varejista de médio porte sobre características do comportamento empreendedor. No estudo evidenciou-se que o indivíduo empreendedor não é alguém com atributos intelectuais mais avantajados, mas sim uma pessoa que consegue evidenciar oportunidades e desenvolvê-las quando outras pessoas só percebem ameaças e incertezas. Em concordância com esta ideologia, Barros e Forte (2004) apontam que o pensamento estratégico não se limita a grandes gestores de multinacionais e grandes negócios, o empreendedor usa seus pontos fortes para transformar açôes dentro de seu ambiente de trabalho e fora, em mudanças que acompanham as exigências do mercado, não importando o tamanho da empresa.

Somando-se a isso Dolabela (1999) sugere que as habilidades e capacidades para um indivíduo criar uma empresa deveriam ser desenvolvidas em alunos de todos os graus de ensino, do primeiro ao terceiro, sendo que o foco seria evoluir a capacidade do aluno a desvendar novas oportunidades. $\mathrm{O}$ mesmo autor ressalta que os pais guiam os filhos para possuir empregos que ofereçam segurança, garantia, estabilidade. Mas para o desenvolvimento de um país os jovens têm que estar dotados de capacidades, como: gerar seu próprio emprego, inovar, gerar riqueza, assumir riscos, autonomia, independência.

Em relação ao processo de formação das características, verifica-se que tanto a formação educacional de nível superior quanto a experiência de vida contribuem para o desenvolvimento das características (MARTINS-SILVA; SILVA; SILVA, 2016). Nesse sentido, a universidade tem importante papel no desenvolvimento do comportamento empreendedor, pois durante os estudos o aluno conhece procedimentos que o influenciam na sua capacidade de explorar coisas que impulsionam sua vida acadêmica e futura vida profissional (SINGER; AMORÓS; ARREOLA, 2015). 
A relação entre teoria e prática no espaço universitário, segundo Guimarães e Lima (2016), não é de hoje que se encontra pautada no campo dos processos voltados para área do empreendedorismo, sendo um requisito primordial na revoluçáo do método de ensinoaprendizagem. Somando-se a isso os autores ressaltam que na atmosfera do empreendedorismo são analisados aspectos como: criação, inovação, revolução, comprometimento, dedicação, motivação e riscos. Lopes e Silva (2014) corroboram que são nas universidades que os alunos devem encontrar ambientes favoráveis para o desenvolvimento da criatividade, inovação e do empreendedorismo, assim aperfeiçoando habilidades de gerar novidades e soluçóes criativas para resolver os problemas e desafios diários que são demandados pelo mercado de trabalho.

Diante disso, para Ribeiro e Bernardes (2014) as características do comportamento empreendedor podem muitas vezes ser facilmente percebidas na maioria das pessoas com inclinação para o empreendedorismo, entre elas estão: a necessidade de realização, inovação, criatividade e motivação.

A seguir as características comportamentais empreendedoras são detalhadas.

\section{CARACTERÍSTICAS COMPORTAMENTAIS EMPREENDEDORAS}

As características empreendedoras segundo Minuzzi, Vargas e Fialho (2016) são abordadas e definidas por diversos autores e geralmente são complementares e não conflitantes. Dornelas (2014) ratifica que as características empreendedoras nada mais são que alguns atributos pessoais em complemento às características sociológicas e ambientais.

Conforme aponta Degen (2009) uma característica evidente no empreendedor é sua afliçáo por mudanças, desejo de fazer as coisas acontecerem. $\mathrm{O}$ autor relata que o dramaturgo irlandês Bernard Shaw argumentava que o homem racional se adapta ao mundo em que vivemos sem questionamento. Porém, o homem irracional tenta adaptar o mundo a si. Diante disso, sem os empreendedores inconformados com o mundo não teríamos luz, água potável, telefone, rádio, etc.

Estes argumentos ratificam a afirmação de McClelland (1972), em que o autor elucida a existência de dois grupos de pessoas classificadas de acordo com suas características comportamentais, um, em que se encaixa a maioria, são aqueles que não estão dispostos a se sacrificar para conseguir alcançar seus objetivos, já o outro, grupo pertencente a minoria, tendem a juntar esforços para alcançar um objetivo pessoal. Estas pessoas fazem as coisas acontecerem e podem ser denominadas empreendedores.

Greatti e Senhorini (2000) explanam que as características empreendedoras são fundamentais para o profissional que almeja se consolidar no mercado de trabalho, já que o mercado demanda de pessoas mais criativas, que saibam assumir riscos, que possuam iniciativa própria para a resoluçáo dos conflitos e que sejam mais persistentes quanto aos seus objetivos. O funcionário, estudante, empresário e, principalmente, as pessoas que querem entrar em um novo ramo de negócio devem ser dotadas destas características.

Diante de um estudo sobre empreendedorismo, Baron e Shane (2007) argumentam que existe um entendimento sobre um conjunto de atitudes presentes no individuo empreendedor. São apresentadas três variáveis, a primeira de nível individual (técnicas, 
motivaçóes e características dos empreendedores); por sequência de nível interpessoal ou grupal (ideias, informaçóes de outras pessoas, clientes, potenciais funcionários, eficácia nas interaçóes com capitalistas de risco) e, por último de nível social (políticas governamentais, condiçóes econômicas, tecnologia) que permeiam todas as fases do processo empreendedor.

Como mencionado anteriormente existem três variáveis compostas por atitudes presentes nos empreendedores individual, grupal e social, na primeira delas, referida como nível individual, Baron e Shane (2007) indicam que é formada pelas características empreendedoras. Muitos autores pesquisaram e estudaram o indivíduo para entender e dar sua contribuição sobre quais características o indivíduo empreendedor tem em comum e o que os difere com outros indivíduos.

Neste sentindo, os estudos científicos elucidados por David McClelland descrevem a teoria empreendedora, no qual é composta por três comportamentos em que estão dispostas as CCE's. No intuito de agregar as pesquisas sobre empreendedorismo McClelland formou parcerias, uma delas foi originada a pedido da USAID (United States Agency for International Desenvelopment), na qual realizaram um estudo que apontava a identificação de características comportamentais empreendedoras em países emergentes. A partir desse estudo foi desenvolvido um questionário capaz de mensurar essas características, a partir dos três grupos de comportamento Realização, Planejamento e Poder, (MANSFILELD et al., 1987).

Conforme ilustrado no Quadro 1, tornaram-se dez CCE's na qual cada qual está inserida dentre as três dimensões respectivas.

Quadro 1 - Características comportamentais empreendedoras

\begin{tabular}{|c|c|c|}
\hline CATEGORIAS & CARACTERÍSTICAS & COMPORTAMENTOS \\
\hline \multirow{5}{*}{ REALIZAÇÓES } & $\begin{array}{c}\text { Busca de oportunidades } \\
\text { e iniciativas }\end{array}$ & $\begin{array}{l}\text { Viabiliza e atua em novas oportunidades de } \\
\text { negócios. } \\
\text {. } \\
\text { Age antes que aconteça algum imprevisto. }\end{array}$ \\
\hline & Presciência & $\begin{array}{l}\text { Realiza repetidas açóes para solucionar um } \\
\text { desafio ou superar um obstáculo. } \\
\text {. } \quad \text { Muda de estratégia para alcançar um objetivo. }\end{array}$ \\
\hline & Correr riscos calculados & $\begin{array}{l}\text { Enfrenta situaçóes que indicam um desafio e } \\
\text { ou risco moderado. } \\
\text { Calcula com precedência os riscos a ser } \\
\text { tomados. } \\
\text { Segura medidas para reduzir os riscos e } \\
\text { controlar resultados. }\end{array}$ \\
\hline & $\begin{array}{c}\text { Exigência de qualidade } \\
\text { e eficiência }\end{array}$ & $\begin{array}{l}\text { Encontra as melhores maneiras de fazer as } \\
\text { coisas mais rápido e mais barato. } \\
\text { Age com proposito de atender padrôes de } \\
\text { excelência melhorando seu desempenho. }\end{array}$ \\
\hline & Comprometimento & $\begin{array}{l}\text { Responsabiliza por qualquer problema na } \\
\text { conclusáo de um trabalho. } \\
\text { Realiza um sacrifício pessoal para a conclusão } \\
\text { de um trabalho. }\end{array}$ \\
\hline
\end{tabular}




\begin{tabular}{|c|c|c|}
\hline CATEGORIAS & CARACTERÍSTICAS & COMPORTAMENTOS \\
\hline \multirow{3}{*}{ PLANEJAMENTO } & Busca de informaçóes & $\begin{array}{l}\text { Vai à busca de informações pessoalmente, } \\
\text { sobre concorrentes, fornecedores e clientes. } \\
\text { Usa seus contatos pessoais e de negócios para } \\
\text { obter informaçóes que agreguem. }\end{array}$ \\
\hline & $\begin{array}{l}\text { Estabelecimento de } \\
\text { metas }\end{array}$ & $\begin{array}{l}\text { - Articula claramente objetivos de longo prazo. } \\
\text { Definiçáo e revisáo dos objetivos de curto } \\
\text { prazo. }\end{array}$ \\
\hline & $\begin{array}{l}\text { Planejamento e } \\
\text { monitoramento } \\
\text { sistemático }\end{array}$ & $\begin{array}{l}\text { Organiza uma grande tarefa em tarefas } \\
\text { menores. } \\
\text { Arquiva registros financeiros para futuramente } \\
\text { tomar decisões. } \\
\text {. Revisa seus trabalhos para atender as normas } \\
\text { estabelecidas. }\end{array}$ \\
\hline \multirow[t]{2}{*}{ PODER } & $\begin{array}{l}\text { Persuasão e rede de } \\
\text { contatos }\end{array}$ & $\begin{array}{l}\text { - Usar diversas estratégias para persuadir e } \\
\text { influenciar outras pessoas. } \\
\text { Usas seus contatos pessoais e de negócios para } \\
\text { alcanças seus objetivos. }\end{array}$ \\
\hline & $\begin{array}{l}\text { Independência e } \\
\text { autoconfiança }\end{array}$ & $\begin{array}{l}\text { Busca autonomia e controle das regras. } \\
\text { Demonstra confiança em realizar tarefas e } \\
\text { desafios difíceis. }\end{array}$ \\
\hline
\end{tabular}

Fonte: elaborada pelos autores com base em MSI (1990, p. 80-81).

Desta forma, Minuzzi, Vargas e Fialho (2016), afirmam que no conjunto de características formado pela dimensão realização, estas características estão diretamente ligadas ao desafio pessoal de cada indivíduo; no conjunto planejamento, estão associadas com o modo de realizar cada trabalho ou tarefa; já no último conjunto poder contém as características referentes à influência ou persuasão com as pessoas, age de acordo para manter relaçóes comerciais.

Nesse contexto, ao visualizar as universidades como um sistema educacional a mesma é uma área central de intervenção ao desenvolvimento de características empreendedoras, que podem levar o aluno ao desenvolvimento um comportamento mais empreendedor (DINIS et al., 2013).

\section{PROCEDIMENTOS METODOLÓGICOS}

A abordagem utilizada na presente pesquisa é quantitativa, tipo descritiva. A abordagem quantitativa pode ser usada em estudos de grandes aglomerados de dados e de conjuntos demográficos, partindo de um contexto a ser descoberto, e construída a partir de um fenômeno social (SAMPIERI; COLLADO; LÚCIO, 2013). A pesquisa do tipo descritiva procura descrever as características de uma determinada população ou os fatos e fenômenos de uma realidade, o que pode proporcionar uma maior familiaridade com o problema, tornando-o mais explícito e favorecendo o aprimoramento de ideias e considerações dos mais variados aspectos ligados ao fato estudado (TRIVIÑOS, 1987). 
O instrumento utilizado refere-se as características comportamentais empreendedoras (CCE's) desenvolvido a partir dos estudos de McClelland (MANSFIELD et al., 1987) com o objetivo de identificar as características comportamentais empreendedoras dos discentes. Este questionário é baseado nas 10 CCE's de McClelland (MSI, 1990), composto por 55 afirmaçóes. $\mathrm{O}$ instrumento foi respondido de acordo com uma escala de 5 pontos Likert, correspondendo a seguinte gradação: $1=$ nunca, $2=$ raras vezes, $3=$ as vezes, $4=$ frequentemente e 5 = sempre. De acordo com sua percepção, diante de cada uma das 55 assertivas que compóem o instrumento da seguinte forma (Quadro 2):

Quadro 2 - Características e questóes do instrumento das CCE's

\begin{tabular}{|c|c|c|c|c|c|c|}
\hline CCE & \multicolumn{7}{|c|}{ QUESTÕES } \\
\hline Busca de oportunidades e iniciativa & Q1 & Q12 & Q23 & Q34* & Q45 & FC \\
\hline Persistência & Q2 & Q13 & Q24 & Q35* $^{*}$ & Q46 & FC \\
\hline Comprometimento & Q3 & Q14 & Q25 & Q36 & Q47* & FC \\
\hline Exigência de qualidade e eficiência & Q4 & Q15 & Q26 & Q37 & Q48 & - \\
\hline Correr riscos calculados & Q5 & Q16 & Q27 & $\mathbf{Q 3 8}^{*}$ & Q49 & FC \\
\hline Estabelecimento de metas & Q6 & Q17* & Q28 & Q39 & Q50 & FC \\
\hline Busca de informaçóes & Q7 & Q18 & Q29* & Q40 & Q51 & FC \\
\hline Planejamento e monitoramento sistemáticos & Q8 & Q19 & Q30 & Q41* & Q52 & FC \\
\hline Persuasão e redes de contato & Q9 & Q20* & Q31 & Q42 & Q53 & FC \\
\hline Independência e autoconfiança & Q10 & Q21* & Q32 & Q43 & Q54 & FC \\
\hline
\end{tabular}

* Questóes negativas.

Fonte: adaptado de Mansfield et al., 1987.

$\mathrm{O}\left({ }^{*}\right)$ do Quadro 2 corresponde às questóes negativas em que a pontuação deve ser subtraída do resultado final da respectiva característica e deve-se acrescentar 6 (seis) pontos ao final do somatório. As questóes de número 11, 22, 33, 44 e 55 correspondem ao "Fator de Correção", utilizado para evitar que, muitas vezes de modo inconsciente, o respondente apresente uma autoimagem excessivamente favorável. O fator de correção é utilizado se o somatório da pontuação dessas questôes for igual ou superior a 20 (vinte) pontos. Se isso ocorrer, todas as CCE's devem ser corrigidas com a subtração dos pontos correspondentes (MANSFIELD et al., 1987). No Quadro 3 consta o fator de correção para as CCE's.

Quadro 3 - Fator de correção para as CCE's

\begin{tabular}{|c|c|}
\hline Se o a pontuaçáo do Fator de Correçáo é & $\begin{array}{c}\text { Subtraia o seguinte número de correçáo da } \\
\text { pontuaçáo total de cada competência }\end{array}$ \\
\hline 24 ou 25 & 7 \\
\hline 22 ou 23 & 5 \\
\hline 20 ou 21 & 3 \\
\hline 19 ou menos & 0 \\
\hline
\end{tabular}

Fonte: elaborado pelos autores com base em Mansfield et al. (1987). 
A pontuação máxima é de 25 pontos para cada uma das características. Quando o total for igual ou superior a 15 pontos o indivíduo possui a respectiva característica e é considerado empreendedor (MANSFIELD et al., 1987).

A populaçáo total desta pesquisa é composta por 465 discentes, do curso de graduação em Medicina Veterinária da Universidade Federal de Santa Maria. Para o cálculo do tamanho mínimo da amostra optou-se pela fórmula a seguir (Equaçáo 1), que segundo Fonseca e Martins (1996) é para uma população finita, considerou-se um nível de confiança de $95 \%$ e um erro padrão de 5\%, a amostra mínima calculada foi de 212 indivíduos.

Equação (1)

$$
n=\frac{z_{\alpha / 2}^{2} \cdot p \cdot q \cdot N}{e^{2}(N-1)+Z_{\alpha / 2}^{2} \cdot p \cdot q}
$$

Sendo:

e - erro amostral;

$\mathrm{N}$ - tamanho da população;

$\mathrm{n}$ - amostra mínima

$\mathrm{a}=0,05-$ Nível de Significância

$\mathrm{p}=0,5$ e $\mathrm{q}=0,5$

$\mathrm{Z}_{\alpha / 2}^{2}=1,96$ para um nível de confiança de $95 \%$.

No entanto, no período de coleta de dados que ocorreu nos meses de outubro a novembro de 2016, com entrega pessoal em sala de aula, obteve-se 212 respostas. Destes desconsiderou-se um questionário preenchido de modo incompleto, os demais instrumentos foram considerados aptos para análise.

Após a coleta dos dados realizou-se o processo de tabulação e codificação dos dados. Para tratamento e análise dos dados coletados foram realizados testes estatísticos, utilizando o software Statistical Packagefor the Social Sciences - SPSS ${ }^{\bullet}$ versão 24, nessa ocasião foram analisados quantitativamente e explorados os dados do modelo proposto por McClelland (MANSFIELD et al., 1987).

Os testes estatísticos compreendem estatística descritiva em que foram calculados mínimo, máximo, médias e o desvio padrão de cada característica e dimensão. Em seguida, para estimar a confiabilidade foi medida a consistência interna por meio do coeficiente alfa de Cronbach (SAMPIERI; COLLADO; LUCIO, 2013).

$\mathrm{O}$ valor do coeficiente alfa de Cronbach pode variar de 0 a 1 , sendo que, quanto mais próximo de 1 , melhor a confiabilidade, pois, maior será a consistência interna do instrumento ou maior a congruência entre os itens, indicando a homogeneidade da medida do mesmo fenômeno (MATTHIENSEN, 2011). 


\section{ANÁLISE DOS RESULTADOS}

Nesta etapa do trabalho apresenta-se a análise dos resultados, apurados após a aplicação dos questionários aos discentes do curso de graduação em Medicina Veterinária, no intuito de responder os objetivos estabelecidos no estudo.

Salienta-se que os dados obtidos na coleta, por meio do questionário de Mansfield et al. (1987), tem metodologia própria para análise, que prevê um fator de correção aplicado aos questionários que apresentarem uma supervalorização das características. Na Tabela 1 demonstra-se os totais e percentuais de questionários que necessitaram do fator de correção.

Tabela 1 - Fator de correção

\begin{tabular}{llllllllll}
\hline \multicolumn{3}{l}{ No de casos por faixa de pontos } & \multicolumn{7}{c}{ \% de casos por faixa de pontos } \\
\hline Até 19 & $\mathbf{2 0 - 2 1}$ & $\mathbf{2 2 - 2 3}$ & $\mathbf{2 4 - 2 5}$ & Total & Até 19 & $\mathbf{2 0 - 2 1}$ & $\mathbf{2 2 - 2 3}$ & $\mathbf{2 4 - 2 5}$ & Total \\
\hline 192 & 17 & 1 & 1 & 211 & $90,8 \%$ & $8,4 \%$ & $0,4 \%$ & $0,4 \%$ & $100 \%$ \\
\hline
\end{tabular}

Fonte: elaborado pelos autores.

A partir da Tabela 1 constata-se que para aproximadamente 91\% dos alunos não foi necessário o fator de correção, o que revela que os mesmos não criaram uma imagem favorável das suas características comportamentais empreendedoras.

\subsection{PERFIL DOS PESQUISADOS}

A amostra é composta por 211 discentes de graduação, o que representa 45,37\% da população, sendo 57 pessoas do gênero masculino (27,02\%) e 154 do gênero feminino (72,98\%). No que se refere a faixa etária 70,6\% (149) possuem até 23 anos. Em relação ao estado civil, os solteiros representam 94,8\% dos respondentes. Quanto ao trabalho, 73,4\% (155) dos respondentes afirmam que não trabalham. Quanto ao questionamento sobre já ter cursado disciplinas relacionadas ao empreendedorismo $72 \%$ (152) dos respondentes afirmaram nunca ter cursado quaisquer disciplinas relacionadas ao empreendedorismo.

\subsection{CARACTERÍSTICAS COMPORTAMENTAIS EMPREENDEDORAS}

A análise dos resultados iniciou com o cálculo da confiabilidade, foi medida a consistência interna por meio do coeficiente alfa de Cronbach (SAMPIERI; COLLADO; LUCIO, 2013). O coeficiente alfa de Cronbach é calculado pela seguinte Equação 2:

Equação (2)

$\alpha=\frac{k}{k-1}\left[\frac{\sigma_{\tau}^{2}-\Sigma_{i=1 \sigma_{i}^{2}}^{k}}{\sigma_{\tau}^{2}}\right]$

Que corresponde a:

$\mathrm{k}$ corresponde ao número de itens do questionário;

$\sigma^{\wedge} 2 \mathrm{i}$ corresponde soma das variâncias de cada item; 
$\sigma^{\wedge} 2 \mathrm{t}$ corresponde a variância total do questionário, determinada como a soma de todas as variâncias.

$\mathrm{O}$ alfa de Cronbach obteve $\alpha=0,827$. Deste modo, os valores resultantes da aplicação dos questionários com os 211 discentes são confiáveis (SAMPIERI; COLLADO; LUCIO, 2013).

Em seguida verificou-se mínimo, máximo, média, desvio padrão e variância de cada característica e dimensão das CCE’s, dos discentes participantes. No Quadro 4 apresenta-se a estatística descritiva das CCE's.

Quadro 4 - Estatística descritiva CCE's

\begin{tabular}{|c|c|c|c|c|c|c|}
\hline Inst. & Características/Dimensóes & Mínimo & Máximo & Média & $\begin{array}{l}\text { Desvio } \\
\text { Padráo }\end{array}$ & Variância \\
\hline \multirow{13}{*}{ Û̉ } & $\begin{array}{l}\text { Busca de oportunidades e } \\
\text { iniciativa }\end{array}$ & 11,00 & 24,00 & 17,5166 & 2,54735 & 6,489 \\
\hline & Persistência & 9,00 & 22,00 & 16,8531 & 2,27664 & 5,183 \\
\hline & Comprometimento & 9,00 & 25,00 & 18,5545 & 3,00802 & 9,048 \\
\hline & $\begin{array}{l}\text { Exigência de qualidade e } \\
\text { eficiência }\end{array}$ & 11,00 & 24,00 & 17,9526 & 2,64892 & 7,017 \\
\hline & Correr riscos calculados & 10,00 & 25,00 & 16,6209 & 2,33775 & 5,465 \\
\hline & Estabelecimento de metas & 9,00 & 25,00 & 19,5071 & 3,14320 & 9,880 \\
\hline & Busca de informaçóes & 10,00 & 25,00 & 18,9810 & 3,05031 & 9,304 \\
\hline & $\begin{array}{l}\text { Planejamento e monitoramento } \\
\text { sis. }\end{array}$ & 9,00 & 25,00 & 17,3744 & 2,56480 & 6,578 \\
\hline & Persuasão e redes de contato & 9,00 & 24,00 & 16,4882 & 2,72792 & 7,442 \\
\hline & Independência e autoconfiança & 10,00 & 24,00 & 17,4313 & 2,84166 & 8,075 \\
\hline & Realização & 12,00 & 21,60 & 17,4995 & 1,78570 & 3,189 \\
\hline & Planejamento & 11,00 & 24,00 & 18,6019 & 2,32641 & 5,412 \\
\hline & Poder & 11,00 & 23,50 & 16,9597 & 2,17497 & 4,731 \\
\hline
\end{tabular}

No válido (Listwise) 211.

Fonte: elaborado pelos autores.

A partir do Quadro 4 é possível identificar as pontuações mínimas e máximas de cada característica e dimensão, assim como as médias, desvio padrão e variância. Para as características o limite máximo é de 25 pontos, na característica de persistência obteve-se pontuação máxima de " 22 ", menor dentre as dez características.

A maior média foi registrada na característica estabelecimento de metas "19,50", que para McClelland (MSI, 1990) significa que, para esses discentes, objetivos e metas são desafiantes e tem um significado pessoal; as metas são claras, objetivas e definidas a longo prazo; as metas estabelecidas a curto prazo são mensuráveis. A menor média ocorreu na característica persuasão e redes de contato “16,48”, o comportamento do indivíduo que apresenta persuasão e redes de contanto é discutir estratégias antecipadamente para 
influenciar e persuadir os outros; utilizar-se de pessoas-chave para atingir objetivos propostos (MSI, 1990). O menor desvio padrão ocorreu na dimensão realização, que contempla as cinco características iniciais e demonstra singularidade entre os resultados.

$\mathrm{Na}$ Figura 1 constam as médias das características comportamentais empreendedoras e das respectivas dimensōes dos discentes.

Figura 1 - Média das CCE’s

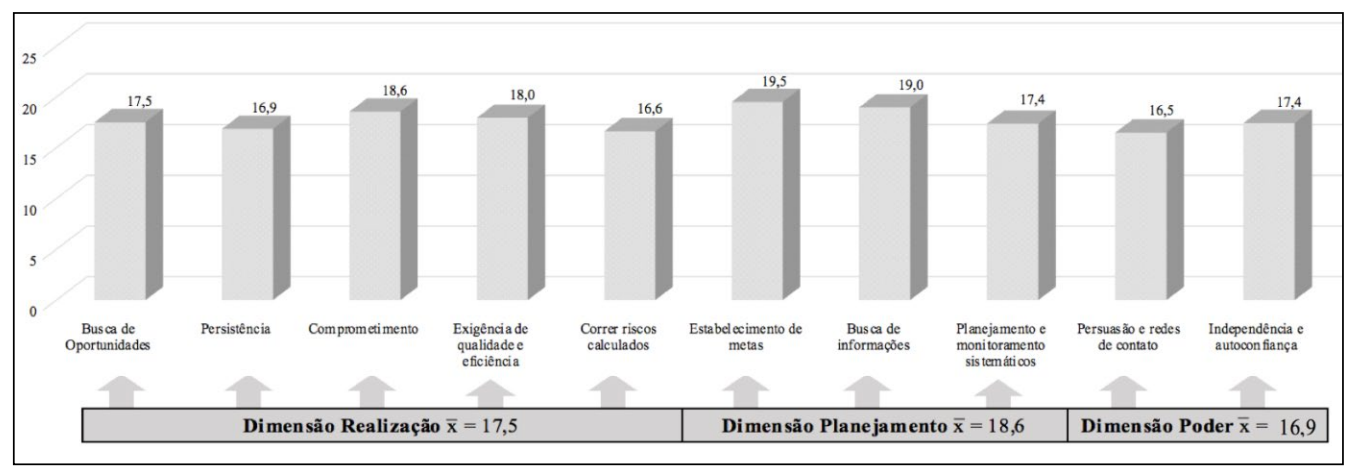

Fonte: elaborado pelos autores.

A partir da média verifica-se que os discentes pesquisados possuem as características $(\geq 15,0)$, e que a dimensão com maior pontuação foi planejamento "18,6". Na Figura 2 percebe-se que as características estão na zona de 15,0 e 20,0 pontos.

Figura 2 - Zona de pontuação das médias das CCE’s

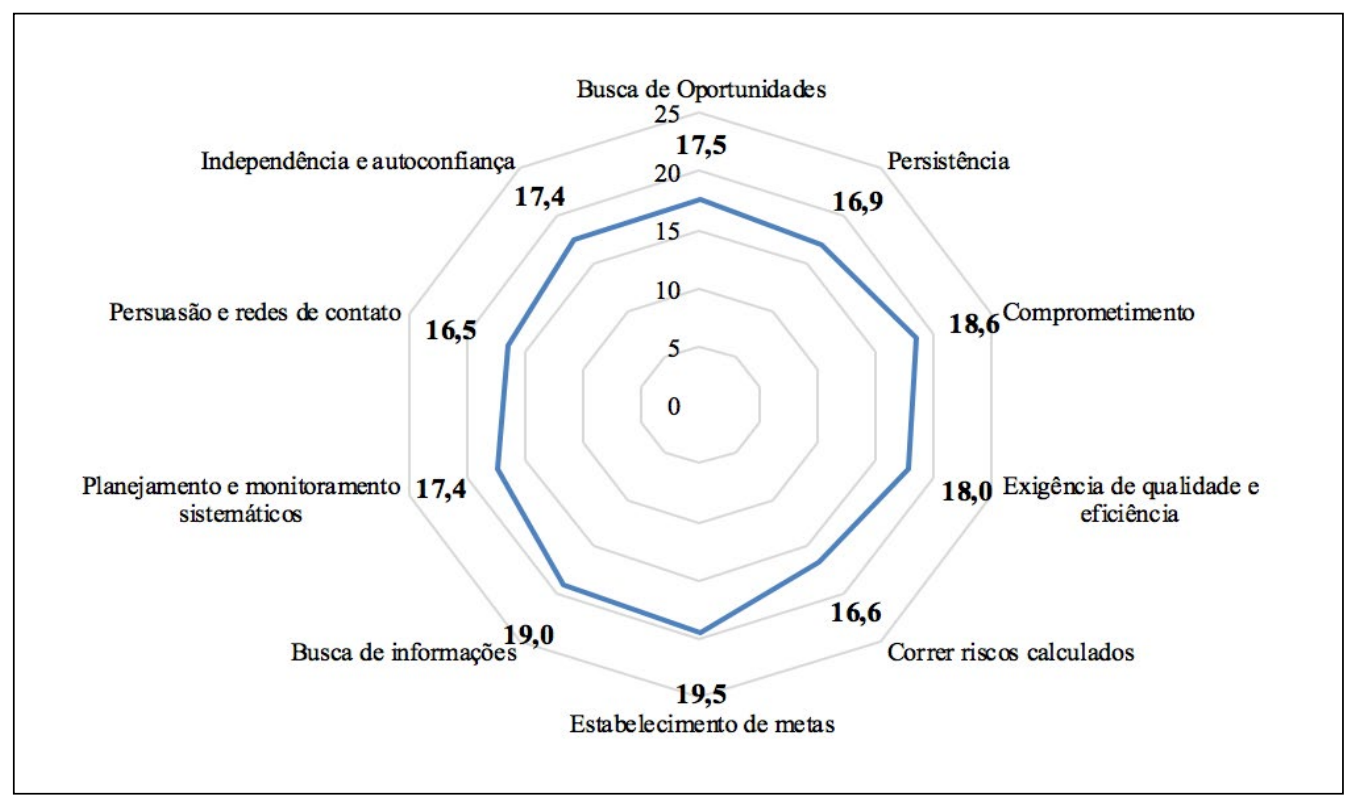

Fonte: elaborado pelos autores. 
Ao considerar 25,00 como a pontuação máxima e 15,00 como a pontuação mínima para a presença das características (MANSFIELD et al, 1987), constata-se, por meio da média, que as características dos discentes pesquisados podem ser aprimoradas e desenvolvidas, tendo em vista o limite máximo dessa pontuação. Para Minuzzi, Vargas e Fialho (2016) graduandos necessitam desenvolver as CCE's para que possam competir no mercado, em que o principal desafio é a necessidade de profissionais flexíveis e adaptáveis ao mercado.

\subsection{COMPARATIVO DAS CCE'S ENTRE OS GÊNEROS}

Levando em consideração a variável gênero, se infere que as características comportamentais empreendedoras podem se expressar de diferentes maneiras, para Machado (2008) o empreendedorismo não é privilégio de nenhum dos gêneros, masculino ou feminino, pois ambos demonstram competências empreendedoras, seja por oportunidade ou por necessidade. Diante disso, as características comportamentais empreendedoras devem constar nos alunos indiferente do gênero a que pertençam, enquanto futuros empreendedores em suas respectivas áreas de atuação. Na Figura 3 apresenta-se as pontuaçóes das características comportamentais empreendedoras para os respectivos gêneros.

Figura 3 - Média das CCE’s por gênero

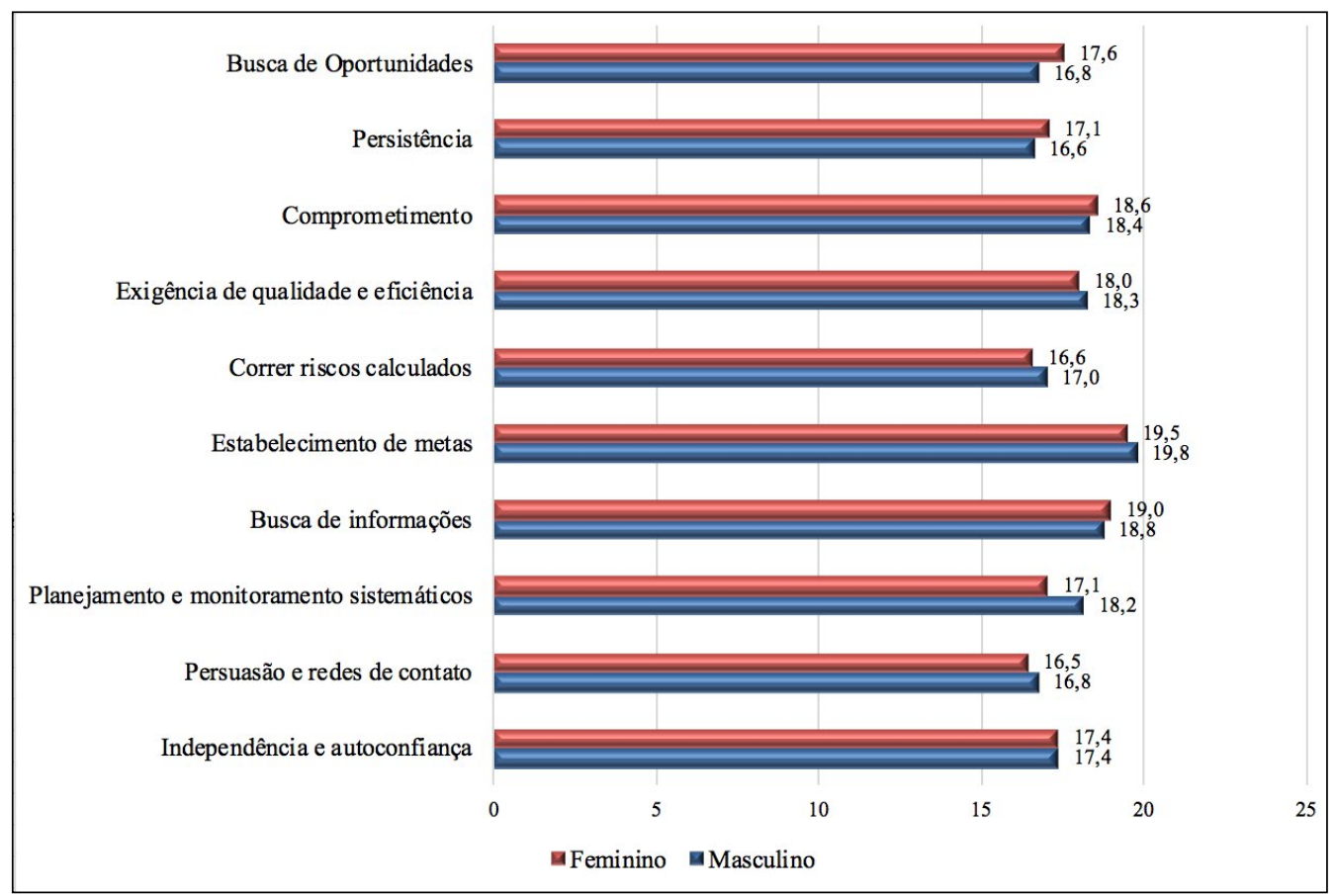

Fonte: elaborado pelos autores.

A partir da Figura 3 infere-se que tanto os discentes do gênero feminino quanto do masculino apresentam as dez características $(\geq 15,0)$. Conforme comparação das médias da 
CCE's, constata-se que, de forma geral, os homens apresentam maiores médias em cinco características, quais sejam: Exigência de qualidade e eficiência, Correr riscos calculados, Estabelecimento de metas, Planejamento e monitoramento sistemáticos, e, Persuasăo e redes de contato. No entanto, ressalta-se que as mulheres apresentaram maiores médias em quatro características, sendo: Busca de oportunidades e iniciativa, Persistência, Comprometimento e Busca de informaçóes. A característica de independência e autoconfiança obteve valor equivalente em ambos gêneros.

Em seguida foi realizada a comparação das pontuações entre as dimensōes Realizações, Planejamento e Poder, diante dos gêneros dos discentes pesquisados (Figura 4).

Figura 4 - Média das dimensôes por gênero

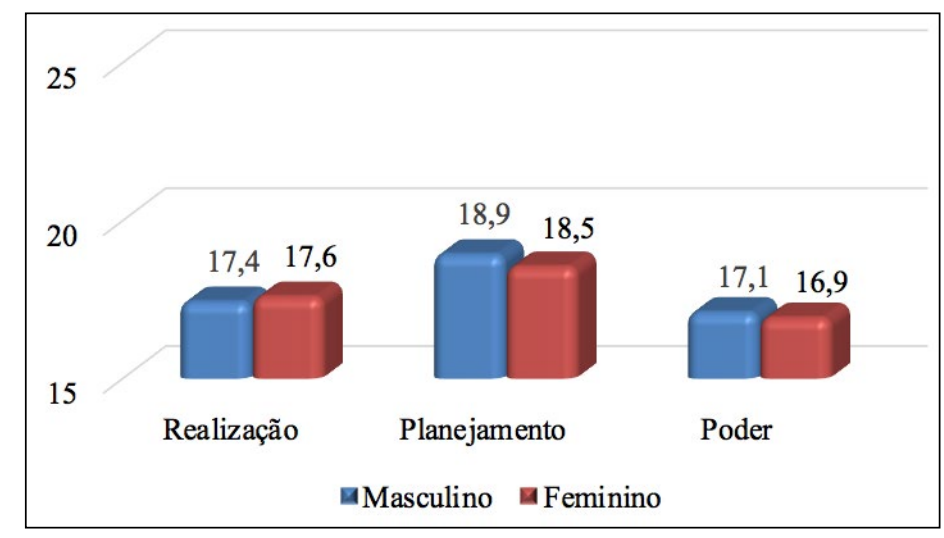

Fonte: elaborado pelos autores.

Diante da comparação dos gêneros por dimensão, infere-se que na dimensão Realização (Figura 4) as mulheres obtiveram maior pontuação, McClelland (1972) afirma que pessoas que manifestam necessidades de realização desejam alcançar metas de difícil alcance e exigem elevado padrão de sucesso, assim como o domínio de tarefas complexas.

Nas demais dimensóes, Planejamento e Poder, os homens obtiveram pontuaçáo superior. Para Gomes (2011) o planejamento é considerado a base para o sucesso, dentro e fora da sala de aula. Nesse sentido, o comportamento empreendedor pode oportunizar ao estudante enxergar e avaliar determinada situaçáo, assumindo uma posição proativa frente a ela, capacitando-o a elaborar e planejar formas e estratégias de interagir com aquilo que ele passou a perceber (LOPES, 2014). A dimensão Poder, para McClelland (1972), é descrita como uma preocupaçáo com o controle dos meios de influenciar os demais, importante náo confundir a dimensão poder com comportamentos abusivos por parte do indivíduo.

Infere-se que para os diferentes gêneros, feminino e masculino, as pontuaçóes para cada característica e dimensóes obtiveram similitude. A maior discrepância entre a pontuação mínima e máxima é observável na característica Planejamento e monitoramento sistemáticos, com diferença de " 1,1 ". As demais características apresentam diferença inferior a " $1,00 "$ ". 
Relacionando esses resultados ao fato de que $72 \%$ dos respondentes nunca cursou quaisquer disciplinas relacionadas ao empreendedorismo, infere-se que, apesar dos discentes apresentarem as dez CCE's, a universidade empreendedora ainda náo é concreta na instituição pesquisada, quando se considera que a mesma deva permear por todos cursos (CLARK, 2006). Esclarece-se que não ter cursado uma disciplina de Empreendedorismo não, necessariamente, quer dizer que esses indivíduos não tenham ou que ainda não possam desenvolver características empreendedoras. A questão é que, nesta pesquisada, poucos alunos já passaram por alguma capacitação acerca de empreendedorismo.

\section{CONSIDERAÇÓES FINAIS}

Os discentes, para Minuzzi, Vargas e Fialho (2016), necessitam desenvolver as CCE's para que possam competir no mercado, na qual um dos principais desafios é a necessidade de profissionais flexíveis e adaptáveis ao ambiente de negócios. Isso corrobora o desenvolvimento do comportamento empreendedor e a ideia da universidade empreendedora, que para Clark, o empreendedorismo deve permear por toda instituiçáo.

Diante do contexto abordado e considerando a importância do empreendedorismo para o desenvolvimento de uma nação, resgata-se o objetivo deste estudo que consiste em analisar as características comportamentais empreendedoras mais evidentes nos discentes de graduação do curso de Medicina Veterinária da UFSM, que foi contemplado, visto que se verificou que a maior média foi registrada na característica estabelecimento de metas, que para McClelland (MSI, 1990) infere que, para esses discentes, objetivos e metas são desafiantes e tem um significado pessoal; as metas são claras, objetivas e definidas a longo prazo; as metas estabelecidas a curto prazo são mensuráveis.

Quanto aos objetivos específicos, foi possível traçar um perfil dos discentes pesquisados, sendo que a amostra era composta 211 discentes de graduação em Medicina Veterinária, destes, a maioria são mulheres, com até 23 anos e solteiras. Destaca-se ainda que, a maioria dos discentes participantes não trabalha e nunca cursou qualquer disciplina relacionada ao empreendedorismo. Em relação as características comportamentais empreendedoras diante do gênero, os homens obtiveram pontuação superior em cinco características enquanto as mulheres em quatro características. No entanto, é preciso lembrar que não ocorreram diferenças expressivas de média das características e dimensóes dentre os gêneros. Nesse sentido, o gênero não gerou resultados diferentes, neste estudo tanto homens quanto mulheres possuem características empreendedoras semelhantes.

Sendo assim, foi possível verificar que os discentes possuem as dez características comportamentais empreendedoras, no entanto, as mesmas podem ser aprimoradas, visto que, constam na zona de 15 e 20 pontos e a pontuação máxima é de 25 pontos. Relacionando esse resultado ao fato de que $72 \%$ dos respondentes nunca cursaram quaisquer disciplinas relacionadas ao empreendedorismo, infere-se que, apesar dos mesmos apresentarem as dez CCE's, a universidade empreendedora precisa ser desenvolvida na instituição pesquisada, quando se considera que o empreendedorismo deve permear em todos os cursos.

Os resultados obtidos demonstram êxito quanto à definição das características empreendedoras para estudo, visto que, contribuem com informaçóes úteis para a instituição 
pesquisada, que poderá utilizá-las para melhor conhecimento e preparação dos discentes do Curso de Medicina Veterinária.

Uma das principais limitaçóes do presente estudo está relacionada a resistência dos discentes quanto a responder o instrumento, por se tratar de um questionário extenso, composto por 55 assertivas. Além disso, o estudo limitou-se a aplicação do questionário exclusivamente no curso de Medicina Veterinária da UFSM, podendo-se obter resultados diversos se aplicado em outros cursos e em outras instituiçóes.

Por fim, sugere-se a replicação da presente pesquisa em cursos de graduação em Medicina Veterinária em demais instituiçóes de ensino, nacionais e internacionais, para que seja possível estabelecer uma comparação entre os resultados obtidos, considerando também diferenças culturas. Seria interessante também, realizar um acompanhamento longitudinal da evolução dessas características comportamentais nos indivíduos pesquisados.

\section{REFERÊNCIAS}

BARON, R. A.; SHANE, S. A. Empreendedorismo: uma visáo do processo. São Paulo: Thomson Learning, 2007.

BARROS, F. S. O.; FORTE, S. H. A. C. A análise das características empreendedoras versus premissas da escola da estratégia empreendedora: um estudo multicasos no setor de alimentação. Organizaçóes Rurais e Agroindustriais. v. 6, n. 2, 2004.

BRANCHER, I. B.; OLIVEIRA, E. M.; RONCON, A. Comportamento empreendedor: estudo bibliométrico da produção nacional e a influência de referencial teórico internacional. Internext -Revista Eletrônica de Negócios Internacionais da ESPM. Sáo Paulo, v. 7, n. 1, 2012.

BRANDÃO, E. A.; VASCONCELOS, G. M. R.; MUNIZ, R. M. Empreendedorismo e Racionalidade. Revista Pretexto, Belo Horizonte, 2011.

CAMARA, E. C.; ANDALÉCIO, A. M. L. Características empreendedoras: um estudo de caso com farmacêuticos utilizando o modelo de McClelland. Revista de

Empreendedorismo e Gestáo de Pequenas Empresas, v. 1, n. 3, p.64-77, 2012.

CARREIRA, S. S.; FRANZONI, A. B.; ESPER, A. J. F.; PACHECO, D. C.; GRAMKOW, F. B.; CARREIRA, M. F. Empreendedorismo feminino: um estudo fenomenológico. Navus. Revista Gestáo e Tecnologia. Florianópolis, 2015.

CLARK, B. Pursuing the entrepreneurial University. In: AUDY, J. L. N.; MOROSINI, M. C. (Org). Inovaçáo e Empreendedorismo na Universidade. Porto Alegre: EDIPUCRS, 2006.

DEGEN, R. J. O empreendedor: empreender como opção de carreira. São Paulo, SP: Pearson Prentice Hall, 2009. 
DINIS, A.; PAÇO, A.; FERREIRA, J.; RAPOSO, M.; GOUVEIRA, R. R. Psychological characteristics and entrepreneurial intentions among secondary students. Education + Training. v. 55, n 8/9, p. 763-780, 2013.

DOLABELA, F. Oficina do empreendedor. São Paulo, SP: Cultura Editores Associados, 1999.

DOLABELA, F.; FILION, L. J. Fazendo revolução no Brasil: a introdução da pedagogia empreendedora nos estágios iniciais da educação. Revista de Empreendedorismo e Gestáo de Pequenas Empresas, v.3, n.2, 2013.

DORNELAS, J. C. A. Empreendedorismo: transformando ideias em negócios. Rio de Janeiro, RJ, 2014.

EUROMONITOR INTERNATIONAL. Market sizes: number of vets - historic persons. 2015. Disponível em: <http://www.portal.euromonitor.com/portal/statistics/c hangemeasure >. Acesso em: 22 jul. 2018.

FILHO, R. N. L; BRUNI, A. L. Metacognição estimula características empreendedoras? uma análise em profissionais de administração. Race, Joaçaba, v. 14, n. 2, p. 427-450, maio/ago. 2015.

FREITAS, F. J. S. GAMEIRO, A. H. O ensino da administração nos cursos de Medicina Veterinária no Brasil. ARS VETERINARIA, Jaboticabal, SP, v.34, n.1, 029-038, 2018.

GOMES, E. M. F. A importância do planejamento para o sucesso escolar.

Universidade Federal do Tocantins - TO. 2011.

GREATTI, L.; SENHORINI, V. M. Empreendedorismo - uma visão comportamentalista. Anais do I EGEPE, Maringá, Paraná, 2000.

GUIMARÃES, J. C.; LIMA, M. A. M. Empreendedorismo Educacional: Reflexões para um Ensino Docente Diferenciado. Revista Pensamento Contemporâneo em Administraçáo, v. 10, n. 2, p. 34-49, 2016.

HISRICH, R. D.; PETERS, M. P.; SHEPHERD, D. A. Empreendedorismo. 9. ed. Porto Alegre: AMGH, 2014.

LOPES, C. L. J. Educação Empreendedora: Um estudo do projeto de empreendedorismo 10.0 aplicado aos alunos do curso técnico em informática. Revista de Empreendedorismo, inovaçáo e tecnologia, v. 1, 39-44, 2014.

LOPES, K. P. S.; SILVA, D. O. Criatividade empreendedora - seria essa a âncora de um grupo de estudantes formandos? Revista de Carreiras e Pessoas, v. 4, n. 1, p. 2-16, 2014. 
MACHADO, H. V. Tendências do comportamento gerencial da mulher empreendedora. In: Encontro da Anpad (EnAnpad), 32, 2008. Rio de Janeiro. Anais... Rio de Janeiro, 2008.

MANAGEMENT SYSTEMS INTERNATIONAL (MSI). Entrepreneurship training and the strengthening of entrepreneurial performance. Final Report. Submetido por Robert Young, Washington, 1990.

MANSFIELD, R. S.; MCCLELLAND, D. C.; SPENCER, J. L. M.; SANTIAGO, J. The identification and assessment of competencies and other personal characteristics of entrepreneurs in developing countries. Final report. McBer and Compay. Massachusetts, 1987.

MARTINS-SILVA, P. O.; SILVA, C. S.; SILVA JR, A. As competências dos administradores: seu processo de formação e as exigências do mercado de trabalho. Revista Contemporânea de Economia e Gestão. V. 14, v. 2, 2016.

MATTHIENSEN, A. Uso do Coeficiente Alfa de Cronbach em Avaliaçóes por Questionários. EMBRAPA Boa Vista, RR, 2011.

MCCLELLAND, D. C. A sociedade competitiva: realizaçáo \& progresso social. Rio de Janeiro: Expressão e Cultura, 1972.

MINUZZI, C. D. O.; VARGAS, K. S.; FIALHO, C. B. Características comportamentais empreendedoras: em cena os futuros administradores. Revista de Empreendedorismo e Gestáo de Pequenas Empresas, v.5, n.1, 2016.

RIBEIRO, P. E.; BERNARDES, M. A. O papel da universidade no desenvolvimento do comportamento empreendedor em regióes carentes. Revista Eletrônica Gestáo e Serviços, v. 5, n. 2, p. 978-993, 2014.

SAMPIERI, R. H.; COLLADO, C. F.; LUCIO, M. P. B. Metodologia de Pesquisa. 5. ed. Porto Alegre: Penso, 2013.

SINGER, S.; AMORÓS, J. E.; ARREOLA, D. M. Global Entrepreneurship Monitor - 2014 Disponível em: <Global Report. http://www.gemconsortium.org/docs/ download/3616>. Acesso 10 mar. 2016.

SOUZA, I. M.; SANTOS, J. L. S. Empreendedorismo na Gestão Universitária. Revista da Universidade Vale do Rio Verde, Três Coraçōes, v. 11, n. 2, p. 517-526, ago./dez. 2013.

TRIVIÑOS, A. N. S. Introduçáo à pesquisa em ciências sociais: a pesquisa qualitativa em educação. $1^{a}$ ed. Sáo Paulo: Atlas, 1987. 
VIDAL, F. A. B.; SANTOS FILHO, J. L. Comportamento empreendedor do gerente proprietário influenciando na vantagem competitiva de uma empresa varejista de médio porte. In: ENCONTRO ANUAL DA ASSOCIAÇÃO NACIONAL DOS PROGRAMAS DE PÓS-GRADUAÇÃO EM ADMINISTRAÇÃO, 28., 2003, AtibaiaSP. Anais... Atibaia: 2003.

\section{ANEXO - QUESTIONÁRIO}

Caro respondente: Este questionário faz parte de uma pesquisa institucional sobre características empreendedoras dos alunos de graduação da UFSM. O questionário é anônimo, sendo as respostas utilizadas somente para fins acadêmicos. CAAE: 59408016.9.0000.5346.

\section{Dados complementares de suporte}

1. Gênero: ( ) masculino ( ) feminino 2. Idade:

3. Estado Civil:

4. Curso: 5. Semestre:

6. Trabalha ( ) sim ( ) não

7. Já cursou disciplinas de empreendedorismo ( ) sim ( ) não

Responda atentamente cada afirmação e marque a alternativa que descreva você da melhor forma (considere como você é hoje, e não como gostaria de ser)

\begin{tabular}{|c|c|c|c|c|c|}
\hline Questionário de Características Empreendedoras & 总 & 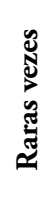 & 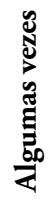 & 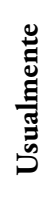 & ڤ̆ \\
\hline 1. Esforço-me para realizar as coisas que devem ser feitas. & 1 & 2 & 3 & 4 & 5 \\
\hline $\begin{array}{l}\text { 2. Quando me deparo com um problema difícil, levo muito tempo para encontrar a } \\
\text { soluçấo. }\end{array}$ & 1 & 2 & 3 & 4 & 5 \\
\hline 3. Termino meu trabalho / atividade a tempo. & 1 & 2 & 3 & 4 & 5 \\
\hline 4. Aborreço-me quando as coisas não são feitas devidamente. & 1 & 2 & 3 & 4 & 5 \\
\hline 5. Prefiro situações em que posso controlar ao máximo o resultado final. & 1 & 2 & 3 & 4 & 5 \\
\hline 6. Gosto de pensar no futuro. & 1 & 2 & 3 & 4 & 5 \\
\hline $\begin{array}{l}\text { 7. Quando começo uma tarefa ou projeto novo, coleto todas as informaçóes } \\
\text { possíveis antes de dar prosseguimento a ele. }\end{array}$ & 1 & 2 & 3 & 4 & 5 \\
\hline 8. Planejo um projeto grande dividindo-o em tarefas mais simples. & 1 & 2 & 3 & 4 & 5 \\
\hline 9. Consigo que os outros me apóiem em minhas recomendaçôes. & 1 & 2 & 3 & 4 & 5 \\
\hline $\begin{array}{l}\text { 10. Tenho confiança que posso estar bem sucedido em qualquer atividade que me } \\
\text { proponha executar. }\end{array}$ & 1 & 2 & 3 & 4 & 5 \\
\hline
\end{tabular}




\begin{tabular}{|c|c|c|c|c|c|}
\hline Questionário de Características Empreendedoras & $\underset{\check{Z}}{\tilde{Z}}$ & 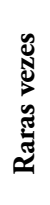 & 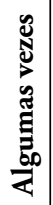 & 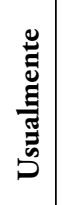 & ڤ̆ \\
\hline 11. Não importa com quem fale, sempre escuto atentamente. & 1 & 2 & 3 & 4 & 5 \\
\hline 12. Faço as coisas que devem ser feitas sem que os outros tenham que me pedir. & 1 & 2 & 3 & 4 & 5 \\
\hline 13. Insisto várias vezes para conseguir que as outras pessoas façam o que desejo. & 1 & 2 & 3 & 4 & 5 \\
\hline 14. Sou fiel às promessas que faço. & 1 & 2 & 3 & 4 & 5 \\
\hline $\begin{array}{l}\text { 15. Meu rendimento no trabalho / atividades é melhor do que o das outras pessoas } \\
\text { com quem trabalho. }\end{array}$ & 1 & 2 & 3 & 4 & 5 \\
\hline $\begin{array}{l}\text { 16. Envolvo-me com algo novo só depois de ter feito o possível para assegurar seu } \\
\text { exito. }\end{array}$ & 1 & 2 & 3 & 4 & 5 \\
\hline 17. Acho uma perda de tempo me preocupar com o que farei daminha vida. & 1 & 2 & 3 & 4 & 5 \\
\hline $\begin{array}{l}\text { 18. Procuro conselhos das pessoas que são especialistas no ramo em que estou } \\
\text { atuando. }\end{array}$ & 1 & 2 & 3 & 4 & 5 \\
\hline $\begin{array}{l}\text { 19. Considero cuidadosamente as vantagens e desvantagens de diferentes alternativas } \\
\text { antes de realizar uma tarefa. }\end{array}$ & 1 & 2 & 3 & 4 & 5 \\
\hline 20. Não perco muito tempo pensando em como posso influenciar as outras pessoas. & 1 & 2 & 3 & 4 & 5 \\
\hline $\begin{array}{l}\text { 21. Mudo a maneira de pensar se os outros discordam energicamente dos meus } \\
\text { pontos de vista. }\end{array}$ & 1 & 2 & 3 & 4 & 5 \\
\hline 22. Aborreço-me quando não consigo o que quero. & 1 & 2 & 3 & 4 & 5 \\
\hline 23. Gosto de desafios e novas oportunidades. & 1 & 2 & 3 & 4 & 5 \\
\hline $\begin{array}{l}\text { 24. Quando algo se interpôe entre o que eu estou tentando fazer, persisto em minha } \\
\text { tarefa. }\end{array}$ & 1 & 2 & 3 & 4 & 5 \\
\hline $\begin{array}{l}\text { 25. Se necessário náo me importo de fazer o trabalho dos outros para cumprir um } \\
\text { prazo de entrega. }\end{array}$ & 1 & 2 & 3 & 4 & 5 \\
\hline 26. Aborreço-me quando perco tempo. & 1 & 2 & 3 & 4 & 5 \\
\hline 27. Considero minhas possibilidades de êxito ou fracasso antes de começar atuar. & 1 & 2 & 3 & 4 & 5 \\
\hline $\begin{array}{l}\text { 28. Quanto mais especificas forem minhas expectativas em relação ao que quero } \\
\text { obter na vida, maiores serão minhas possibilidades de êxito. }\end{array}$ & 1 & 2 & 3 & 4 & 5 \\
\hline 29. Tomo decisóes sem perder tempo buscando informaçóes. & 1 & 2 & 3 & 4 & 5 \\
\hline $\begin{array}{l}\text { 30. Trato de levar em conta todos os problemas que podem se apresentar e antecipo } \\
\text { o que eu faria caso sucedam. }\end{array}$ & 1 & 2 & 3 & 4 & 5 \\
\hline 31. Conto com pessoas influentes para alcançar minhas metas. & 1 & 2 & 3 & 4 & 5 \\
\hline $\begin{array}{l}\text { 32. Quando estou executando algo difícil e desafiador, tenho confiança em seu } \\
\text { sucesso. }\end{array}$ & 1 & 2 & 3 & 4 & 5 \\
\hline 33. Tive fracassos no passado. & 1 & 2 & 3 & 4 & 5 \\
\hline 34. Prefixo executar tarefas que domino perfeitamente e em que me sinto seguro & 1 & 2 & 3 & 4 & 5 \\
\hline $\begin{array}{l}\text { 35. Quando me deparo com sérias dificuldades, rapidamente passo para outras } \\
\text { atividades. }\end{array}$ & 1 & 2 & 3 & 4 & 5 \\
\hline $\begin{array}{l}\text { 36. Quando estou fazendo um trabalho para outra pessoa, me esforço de forma } \\
\text { especial para que fique satisfeita com o trabalho. }\end{array}$ & 1 & 2 & 3 & 4 & 5 \\
\hline $\begin{array}{l}\text { 37. Nunca fico realmente satisfeito com a forma como sáo deitas as coisas; sempre } \\
\text { considero que há uma maneira melhor de fazê-las. }\end{array}$ & 1 & 2 & 3 & 4 & 5 \\
\hline 38. Executo tarefas arriscadas. & 1 & 2 & 3 & 4 & 5 \\
\hline
\end{tabular}




\begin{tabular}{|c|c|c|c|c|c|}
\hline Questionário de Características Empreendedoras & 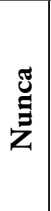 & 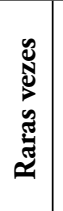 & 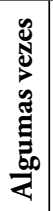 & 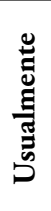 & ڤั \\
\hline 39. Conto com um plano claro de vida. & 1 & 2 & 3 & 4 & 5 \\
\hline $\begin{array}{l}\text { 40. Quando executo um projeto para alguém, faço muitas perguntas para assegurar- } \\
\text { me de que entendi o que quer. }\end{array}$ & 1 & 2 & 3 & 4 & 5 \\
\hline $\begin{array}{l}\text { 41. Enfrento os problemas na medida em que surgem, em vez de perder tempo, } \\
\text { antecipando-os. }\end{array}$ & 1 & 2 & 3 & 4 & 5 \\
\hline $\begin{array}{l}\text { 42. Para alcançar minhas metas, procuro soluçóes que beneficiem todas as pessoas } \\
\text { envolvidas em um problema. }\end{array}$ & 1 & 2 & 3 & 4 & 5 \\
\hline 43. O trabalho que realizo é excelente. & 1 & 2 & 3 & 4 & 5 \\
\hline 44. Em algumas ocasiōes obtive vantagens de outras pessoas. & 1 & 2 & 3 & 4 & 5 \\
\hline 45. Aventuro-me a fazer coisas novas e diferentes das que fiz no passado. & 1 & 2 & 3 & 4 & 5 \\
\hline $\begin{array}{l}\text { 46. Tenho diferentes maneiras de superar obstáculos que se apresentam para a } \\
\text { obtençáo de minhas metas. }\end{array}$ & 1 & 2 & 3 & 4 & 5 \\
\hline $\begin{array}{l}\text { 47. Minha família e vida pessoal são mais importantes para mim do que as datas de } \\
\text { entregas de trabalho determinadas por mim mesmo. }\end{array}$ & 1 & 2 & 3 & 4 & 5 \\
\hline $\begin{array}{l}\text { 48. Encontro a maneira mais rápida de terminar os trabalhos, tanto em casa quanto } \\
\text { no trabalho / faculdade. }\end{array}$ & 1 & 2 & 3 & 4 & 5 \\
\hline 49. Faço coisas que as outras pessoas consideram arriscadas. & 1 & 2 & 3 & 4 & 5 \\
\hline $\begin{array}{l}\text { 50. Preocupo-me tanto em alcançar minhas metas semanais quanto minhas metas } \\
\text { anuais. }\end{array}$ & 1 & 2 & 3 & 4 & 5 \\
\hline $\begin{array}{l}\text { 51. Conto com várias fontes de informaçáo ao procurar ajuda para a execuçáo de } \\
\text { tarefas e projetos. }\end{array}$ & 1 & 2 & 3 & 4 & 5 \\
\hline $\begin{array}{l}\text { 52. Se determinado método para enfrentar um problema náo der certo, recorro a } \\
\text { outro. }\end{array}$ & 1 & 2 & 3 & 4 & 5 \\
\hline $\begin{array}{l}\text { 53. Posso conseguir que pessoas com firmes convicçóes e opinióes mudem seu modo } \\
\text { de pensar. }\end{array}$ & 1 & 2 & 3 & 4 & 5 \\
\hline $\begin{array}{l}\text { 54. Mantenho-me firme em minhas decisóes, mesmo quando as outras pessoas se } \\
\text { opóem energicamente. }\end{array}$ & 1 & 2 & 3 & 4 & 5 \\
\hline 55. Quando desconheço algo, não hesito em admiti-lo. & 1 & 2 & 3 & 4 & 5 \\
\hline
\end{tabular}

